\title{
Concomitant KIT/BRAF and PDGFRA/BRAF mutations are rare events in gastrointestinal stromal tumors
}

\author{
Sabrina Rossi ${ }^{1}$, Marta Sbaraglia ${ }^{1}$, Marta Campo Dell'Orto ${ }^{1}$, Daniela Gasparotto ${ }^{2}$, \\ Matilde Cacciatore ${ }^{1}$, Elena Boscato ${ }^{1}$, Valentina Carraro ${ }^{1}$, Luisa Toffolatti ${ }^{1}$, Giovanna \\ Gallina ${ }^{1}$, Monia Niero ${ }^{1}$, Emanuela Pilozzi ${ }^{3}$, Alessandra Mandolesi ${ }^{4}$, Fausto Sessa ${ }^{5}$, \\ Aurelio Sonzogni ${ }^{6}$, Cristina Mancini ${ }^{7}$, Guido Mazzoleni ${ }^{8}$, Salvatore Romeo ${ }^{1}$, Roberta \\ Maestro $^{2, *}$ and Angelo P. Dei Tos ${ }^{1, *}$ \\ ${ }^{1}$ Department of Pathology and Molecular Genetics, Treviso General Hospital, Treviso, Italy \\ 2 Department of Experimental Oncology, CRO, Aviano, Italy \\ 3 Department of Clinical and Molecular Medicine, University of Rome "La Sapienza", Rome, Italy \\ ${ }^{4}$ Department of Pathology, University of Marche, Ancona School of Medicine, Ancona, Italy \\ ${ }^{5}$ Department of Pathology, Macchi Fondation, Varese, Italy \\ ${ }^{6}$ Department of Pathology, General Hospital, Bergamo, Italy \\ 7 Department of Pathology, Azienda Ospedaliera-Universitaria, Parma, Italy \\ 8 Department of Pathology, General Hospital, Bolzano, Italy \\ * These authors have contributed equally to the work \\ Correspondence to: Angelo P. Dei Tos, email: apdeitos@ulss.tv.it \\ Keywords: GIST, BRAF-mutated GIST, KIT/BRAF concomitant mutations, Imatinib resistance, BRAF VEl antibody, Pathology Section \\ Received: December 30,2015 Accepted: April 04, $2016 \quad$ Published: April 16, 2016
}

\section{ABSTRACT}

AIM: The BRAF mutation is a rare pathogenetic alternative to KIT/PDGFRA mutation in GIST and causes Imatinib resistance. A recent description of KIT and BRAF mutations co-occurring in an untreated GIST has challenged the concept of their being mutually exclusive and may account for $a b$ initio resistance to Imatinib, even in the presence of Imatinib-sensitive KIT mutations. BRAF sequencing is generally limited to KIT/PDGFRA wild-type cases. Hence, the frequency of concomitant mutations may be underestimated.

METHODS: We screened for KIT (exon 9, $11,13,17$ ), PDGFRA (exon 12,14, 18) and BRAF (exon 15) mutations a series of 407 GIST. Additionally, we evaluated the BRAF V600E mutation-specific antibody, VE1, as a surrogate for V600E mutation, on a series of 313 GIST ( 24 on whole sections, 288 cases on tissue array), including 6 cases molecularly ascertained to carry the BRAF V600E mutation.

RESULTS: No concomitant KIT/BRAF or PDGFRA/BRAF mutations were detected. BRAF mutation was detected only in one case, wild-type for KIT/PDGFRA. All the 6 BRAF-mutant cases stained positive with the VE1 antibody. A weak VE1 expression was observed in 14/287 (4.9\%) BRAF wild-type cases, as observed also in 2/6 BRAFmutant cases. Overall in our series, sensitivity and specificity of the VE1 antobody were $100 \%$ and $95.1 \%$, respectively.

CONCLUSION: The concomitance of BRAF mutation with either KIT or PDGFRA mutation is rare in GIST. In these tumors, moderate/strong VE1 immunoreactivity is a valuable surrogate for molecular analysis. Instead, genotyping is warranted in the presence of weak VE1 staining. 


\section{INTRODUCTION}

$\mathrm{BRAF}$ is a serine/threonine protein kinase of the RAF family and belongs to the RAS-RAF-MEK-ERK signalling pathway, which leads to the activation of several cytoplasmic and nuclear targets with transcriptional function, e.g. ETS11, c-JUN and c-MYC. This signalling pathway is triggered by several receptor tyrosine kinases (TKs) such as KIT and PDGFRA. In human cancer the RAS-RAF-MEK-ERK effector pathway is commonly activated, often with gain-of-function mutations in either RAS or RAF gene family members [1].

$B R A F$ mutations have been found in a wide range of tumors (almost $7 \%$ of all cancers), both benign (melanocytic nevi [2], intestinal hyperplastic polyps, sessile serrated polyps/adenomas [3], gangliogliomas and pilocytic astrocytomas [4]), and malignant (hairy cell leukemia [5], melanomas [6], pleomorphic xanthoastrocytomas [4], papillary thyroid carcinomas [7], serous ovarian tumors [8], biliary tract carcinomas [9], colon adenocarcinomas $[10,11]$, lung adenocarcinomas [12], seminomas [13], mastocytosis [14] and gastroenteropancreatic neuroendocrine tumors [15]).

The BRAF mutation has also been reported in a small subset of Gastrointestinal Stromal Tumors (GIST) [16].

GIST are the most common mesenchymal tumor of the gastrointestinal tract [16]. Around $85 \%$ of sporadic primary GIST harbor activating mutations in either the KIT (65\%) or PDGFRA gene (20\%) [17], both encoding type III RTKs, and are variably sensitive to RTKinhibitors, mainly Imatinib. The remaining cases (about $15 \%$ ) represent a heterogeneous group of tumors that generally do not respond to Imatinib and include pediatric GIST, SDH-deficient GIST, NF1-associated GIST, and GIST driven by mutations downstream the TK pathway, e.g. BRAF [16]. The $B R A F$ mutation is a rare event in primary GIST. About $8 \%$ of the cases devoid of KIT/ PDGFRA mutations bear the BRAF mutation [17-21]. Although the use of next generation sequencing (NGS) mutation panels is gaining ground in the clinical diagnostic setting, in the majority of pathology laboratories molecular diagnosis still relies on Sanger sequencing and in most centers the $B R A F$ mutation is investigated after ruling out the most common KIT and PDGFRA mutations. Hence, the frequency of this "alternative mechanism" and its co-existence with KIT/PDGFRA mutations is likely underestimated. $B R A F$-mutated tumors are morphologically and phenotypically indistinguishable from "classical" GIST. However, location-wise, they seem to cluster in the small bowel [17-21]. About $50 \%$ of the BRAF-mutated GIST reported so far fall in the AFIP highrisk category [17-21]. Nevertheless, their rarity and the lack of follow-up data in most series leaves uncertainty as to the correlation between pathologic risk assessment and actual clinical behavior (See Table 1).
While the prognostic role of BRAF is still being debated, its predictive value in response to therapy is well documented. BRAF encodes a kinase molecule downstream of the TK pathways and its mutation constitutively activates the cascade, thereby bypassing the inhibitory effects of Imatinib. The $B R A F$ mutation causes both $a b$ initio resistance to imatinib treatment $[19,22]$ and secondary resistance when it occurs as a secondary event in KIT/PDGFRA-mutated GIST relapsing under therapy $[19,23]$. Recently, a case of GIST with dual BRAF and KIT mutations has been reported in an untreated patient [21], challenging the concept of KIT/PDGFRA and BRAF mutation being mutually exclusive in primary GIST. These authors suggested that the concomitance of KIT and $B R A F$ mutations might explain the resistance phenomena observed in a fraction of GIST carrying Imatinib-sensitive mutations (about $5 \%$ ).

These combined data prompted us to perform a comprehensive evaluation of the involvement of BRAF kinase in GIST development and progression. To this end, we screened a series of 407 GIST cases referred to Treviso General Hospital. In addition, we sought to address the accuracy of immunohistochemistry-based screening to detect $B R A F$ mutation as a surrogate for molecular analysis using BRAF V600E mutation-specific antibody VE1. This reagent has shown good sensitivity and specificity in detecting V600E-mutated cells in most, although not all, of the investigated tumor types [6, 24-49] [50] (See Supplementary Table 1).

\section{RESULTS}

Results from KIT/PDGFRA/BRAF molecular analysis are summarized in Table 2. Only one out of the 407 cases proved to carry a $B R A F$ mutation. This case, a small intestinal untreated GIST, was devoid of KIT or PDGFRA mutations. No case of concomitant KIT and $B R A F$ or PDGFRA and BRAF mutations was found, not even in relapsed cases. Conversely, six concomitant KIT/KIT and one concomitant KIT/PDGFRA mutations were detected in seven metastases that developed under Imatinib treatment (six peritoneal and one hepatic) (Table 3). This supports the notion that BRAF activation compensates for lack of TK mutation in GIST but does not seem to play a relevant role in secondary resistance, where KIT exon 13 and exon 17 mutations seem to be prevalent, in line with published data [16]. In addition, a double mutation was found in a localized untreated rectal GIST; in this case, both mutations involved KIT exon 11 (Lys558Gln and Val560del).

As for the immunohistochemical results, VE1 antibody yielded weak, non-specific, diffuse cytoplasmic staining in the normal gastric/intestinal epithelium and muscularis propria. No nuclear reactivity was observed. A clear-cut positive pattern, with fine granular cytoplasmic accumulation was evident in all four $B R A F$-mutated 
Table 1: BRAF-mutated GIST in the literature

\begin{tabular}{|c|c|c|c|c|c|c|c|c|}
\hline $\mathbf{N}^{\circ}$ & Ref. & Age/Sex & $\begin{array}{l}\text { Primary/ } \\
\text { Relapsed }\end{array}$ & Site & $\begin{array}{l}\text { Size } \\
(\mathrm{cm})\end{array}$ & Morph. & $\begin{array}{l}\text { Mit./ } \\
\text { 50HPF }\end{array}$ & $\begin{array}{l}\text { AFIP } \\
\text { Risk }\end{array}$ \\
\hline 1 & Agaram & $52 / \mathrm{F}$ & Primary & Sm. Int. & 10 & Mixed & 90 & HR \\
\hline 2 & Agaram & $55 / \mathrm{F}$ & Primary & Sm. Int. & 10 & Spindle & 5 & LR \\
\hline 3 & Agaram & $49 / \mathrm{F}$ & Primary & Sm. Int. & 9 & Mixed & 50 & HR \\
\hline 4 & Agaram & $66 / \mathrm{M}$ & Relapsed** & Perit.. & NA & Rhabdo & NA & NA \\
\hline 5 & Agaimy & $70 / \mathrm{M}$ & Primary & Stom. & 0.4 & Spindle & $<5$ & NR \\
\hline 6 & Agaimy & $80 / \mathrm{M}$ & Primary & Sm. Int. & 0.4 & Spindle & $<5$ & NR \\
\hline 7 & Hostein & $53 / \mathrm{M}$ & Primary & Sm. Int. & 20 & Spindle & 6 & HR \\
\hline 8 & Hostein & $38 / \mathrm{M}$ & Primary & Sm. Int. & 2.5 & Mixed & 5 & IR \\
\hline 9 & Hostein & $63 / \mathrm{M}$ & Primary & Stom. & 2.5 & Spindle & NA & NA \\
\hline 10 & Hostein & 78/M & Primary & Stom. & NA & Spindle & 1 & LR \\
\hline 11 & Hostein & $51 / \mathrm{F}$ & Primary & Sm. Int. & 3 & Spindle & 10 & HR \\
\hline 12 & Hostein & $58 / \mathrm{M}$ & Primary & Duod. & 2.5 & Mixed & 1 & IR \\
\hline 13 & Hostein & $58 / \mathrm{M}$ & Primary & Sm. Int. & 2.5 & Spindle & 6 & IR \\
\hline 14 & Hostein & $41 / \mathrm{M}$ & Primary & Sm. Int. & 2.5 & Spindle & 3 & LR \\
\hline 15 & Hostein & $50 / \mathrm{F}$ & Primary & Perit. & 2.8 & Epith. & 50 & HR \\
\hline 16 & Miranda & NA & Primary & Sm. Int. & NA & NA & NA & HR \\
\hline 17 & Miranda & NA & Primary & NA & NA & NA & NA & NA \\
\hline 18 & Falchook & $60 \mathrm{M}$ & Primary & NA & 15 & Spindle & $6 *$ & NA \\
\hline 19 & Zheng & $75 \mathrm{M}$ & Relapsed** & Perit. & NA & Rhabdo & 8 & NA \\
\hline 20 & Rossi & $69 / \mathrm{M}$ & Primary & Sm. Int. & 4.6 & Spindle & 4 & LR \\
\hline 21 & Rossi & $36 / \mathrm{F}$ & Primary & Sm. Int. & 8.5 & Mixed & 3 & UR \\
\hline 22 & Rossi & $66 / F$ & Primary & Sm. Int. & 5.4 & $\begin{array}{l}\text { Mixed } \\
\text { Polym. }\end{array}$ & 8 & HR \\
\hline 23 & Rossi & $63 / \mathrm{M}$ & Primary & Sm. Int. & 11.2 & Mixed & 12 & HR \\
\hline 24 & Rossi & $42 / \mathrm{F}$ & Primary & Sm. Int. & 3.8 & Spindle & 7 & HR \\
\hline 25 & $\begin{array}{l}\text { Rossi } \\
\text { (current) }\end{array}$ & $89 / \mathrm{F}$ & Primary & Sm. Int. & 1.8 & Spindle & 1 & NR \\
\hline
\end{tabular}

Sm. Int. $=$ Small Intestine; Stom. $=$ Stomach; Duod $=$ Duodenum; Perit. $=$ Peritoneum; Rhabdo $=$ Rhabdomyoblastic differentiation; Polym.= Polymorphic; HR= High Risk; IR= Intermediate Risk; LR= Low Risk; NR= No Risk; UR= Unknown Risk;

* In this case the number of mitoses was counted on $10 \mathrm{HPF}$; * Tumor developed under imatinib therapy; 
Table 2: Frequency of $K I T / P D G F R A / B R A F$ mutations in 407 GIST cases

\begin{tabular}{|l|l|l|l|}
\hline Gene & Exon & Cases $(\mathbf{N})$ & Cases $(\%)$ \\
\hline KIT & 11 & 243 & 59.7 \\
\hline KIT & 9 & 39 & 9.6 \\
\hline KIT & 13 & 11 & 2.7 \\
\hline KIT & 17 & 3 & 0.8 \\
\hline PDGFRA & 18 & 37 & 9.1 \\
\hline PDGFRA & 12 & 6 & 1.5 \\
\hline PDGFRA & 14 & 4 & 1 \\
\hline BRAF & 15 & 1 & 0.2 \\
\hline KIT/PDGFRA/BRAF WT & - & 55 & 13.5 \\
\hline KIT/KIT & $11 / 11$ & 1 & 0.2 \\
\hline KIT/KIT & $11 / 13$ & $2^{*}$ & 0.5 \\
\hline KIT/KIT & $11 / 17$ & $3^{*}$ & 0.8 \\
\hline KIT/KIT & $13 / 17$ & $1^{*}$ & 0.2 \\
\hline KIT/PDGFRA & $13 / 18$ & $1^{*}$ & 0.2 \\
\hline Total & - & 407 & 100.0 \\
\hline
\end{tabular}

*Imatinib-treated GIST with double mutations

Table 3: Cases with secondary mutations developed under Imatinib therapy

\begin{tabular}{|c|c|c|c|c|c|c|}
\hline & \multicolumn{3}{|c|}{ Primary tumor } & \multicolumn{3}{|l|}{ Metastasis } \\
\hline & Site & Gene/exon & Mutation & Site & Gene/exon & Mutation \\
\hline 1 & NA & KIT/11 & Met552_Pro573delinsIle & abdominal cavity & KIT/17 & Tyr823Asp \\
\hline 2 & stomach & KIT/11 & Trp557_Glu561del & abdominal cavity & $\mathrm{KIT} / 13$ & Val654Ala \\
\hline 3 & NA & KIT/11 & Asn566_Pro573del & abdominal cavity & KIT/17 & Asn822Lys \\
\hline 4 & duodenum & KIT/11 & Val560_Leu576del & Liver & KIT/13 & Met651Ile \\
\hline 5 & NA & KIT/11 & Glu556_Val560delinsHis & abdominal cavity & KIT/17 & Asn822Lys \\
\hline 6 & stomach & KIT/13 & Lys642Glu & abdominal cavity & KIT/17 & Asn822Lys \\
\hline 7 & stomach & KIT/13 & Lys642Glu & abdominal cavity & PDGFRA/18 & 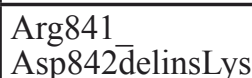 \\
\hline
\end{tabular}

control GIST and the single V600E-mutated case included in our series. This reactivity was weak in two cases, moderate in one and strong in two cases (Figure 1A-1E), with a prevalent homogeneous pattern, but for one case where it was patchy. No reactivity was observed in $B R A F$ wild-type cases. Overall, there was complete agreement in this study series (21 cases) between BRAF V600E molecular analysis and IHC, with a sensitivity and specificity of $100 \%$ (Table 4 ).

To corroborate this initial finding, a second set of 288 GIST, belonging to a population-based study and arranged in tissue arrays, was also analysed. The single $B R A F$-mutant case included in this series turned out to be positive for VE1, with moderate granular staining of the cytoplasm (Fig. 1 F). Two hundred and seventy-three cases were clearly negative. Conversely, weak cytoplasmicpositive staining was observed in 14 cases, three of which belonged to the KIT/PDGFRA/BRAF wild-type subgroup, seven to the KIT-mutated and four to the PDGFRAmutated subgroup. Negativity for $B R A F$ mutation was double checked in these cases. In this second study set, the concordance rate between BRAF V600E molecular analysis and IHC was thus $95.1 \%$, with a sensitivity of $100 \%$ and specificity of $95.1 \%$ (Table 4). Importantly, none of the BRAF-wild-type GIST showed moderate/ strong staining. 
Table 4: VE1 sensitivity and specificity in the first and second study set

\begin{tabular}{|l|l|l|}
\hline & Whole section set & TMA set \\
\hline Cases & 25 & 288 \\
\hline BRAF-mutated cases & 5 & 1 \\
\hline $\begin{array}{l}\text { BRAF-mutated VE1-positive cases } \\
\text { (\% sensitivity) }\end{array}$ & $\begin{array}{l}5 \\
(100)\end{array}$ & $\begin{array}{l}1 \\
(100)\end{array}$ \\
\hline $\begin{array}{l}\text { BRAF-WT VE1-positive cases } \\
\text { (\% specificity) }\end{array}$ & $\begin{array}{l}0 \\
(100)\end{array}$ & $\begin{array}{l}14 \\
(95.1)\end{array}$ \\
\hline
\end{tabular}

Sensitivity $=100.00 \% \quad(95 \%$ CI: $16.55 \%$ to $100.00 \%)$

Specificity $=95.12 \% \quad(95 \%$ CI: $91.95 \%$ to $97.31 \%)$
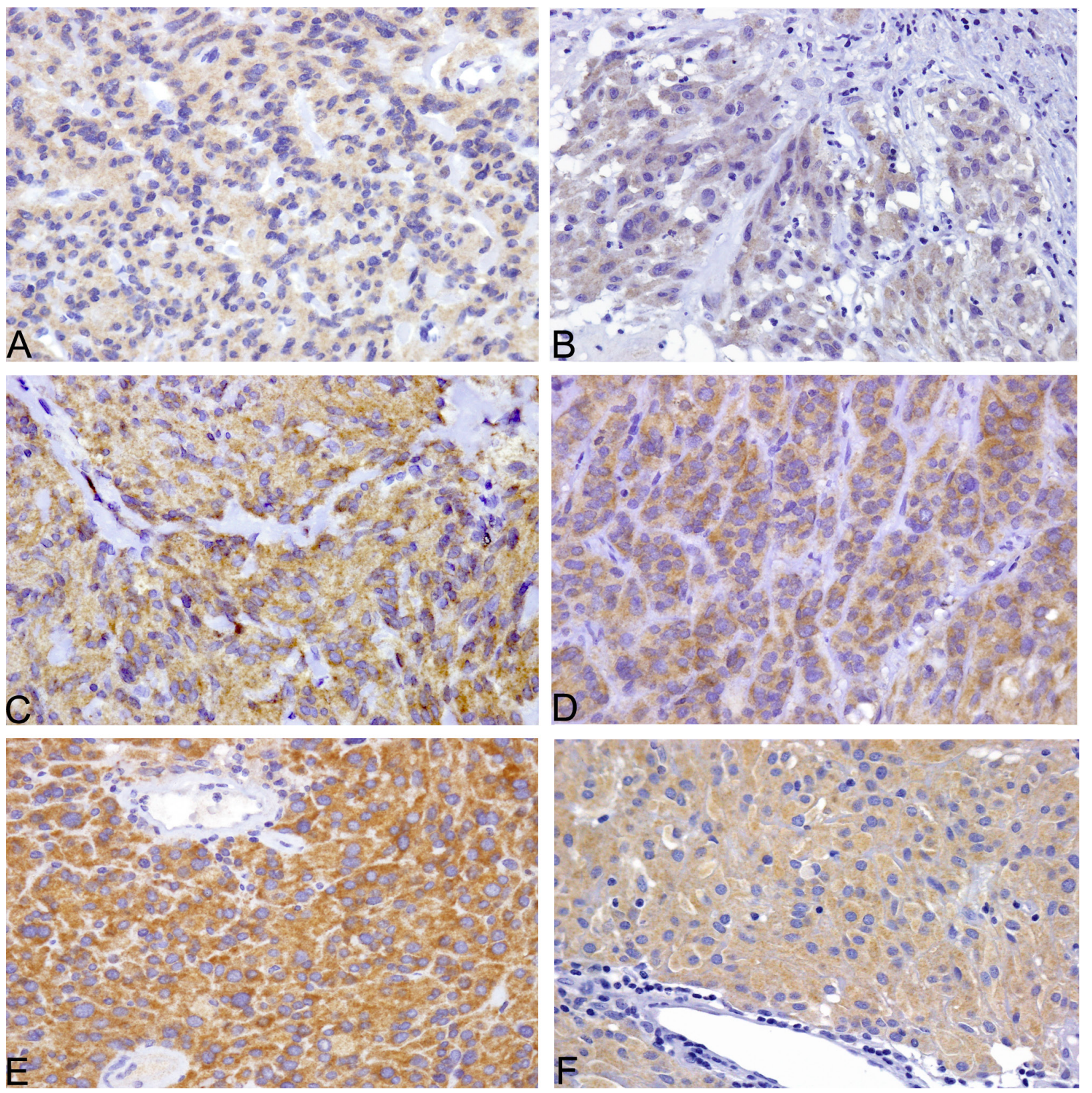

Figure 1: All six BRAF V600E-mutated GIST of the series were VE1 positive, with weak cytoplasmic staining in two cases $(A, B)$, moderate staining in two cases $(C, F)$ and strong staining in two cases $(D, E)$. 


\section{DISCUSSION}

$B R A F$ mutation has been reported in a small subset of primary KIT and PDGFRA wild-type GIST [17-21] and in rare relapsed cases receiving Imatinib therapy $[19,23]$. To date, 22 BRAF-mutated cases have been described, but the actual role of V600E mutation in GIST pathobiology is far from being defined. Except for a few studies [17, $18,20,21], B R A F$ status is usually investigated in KIT/ PDGFRA mutation-negative cases only.

To investigate the relevance of concomitant $B R A F$ and KIT/PDGFRA mutations in primary and secondary resistance to Imatinib, we conducted a molecular study of the hot spots of KIT, PDGFRA and BRAF. Only one case out of the 407 analyzed GIST carried the BRAF V600E mutation. This case was wild-type for KIT/PDGFRA. No concomitant mutations were found in KIT and BRAF or PDGFRA and BRAF. We detected only one double mutation in a localized/untreated context, consisting of a point mutation and a deletion affecting nearby nucleotides in KIT exon 11, similarly to our previous report [51]. Secondary mutations in KIT-mutated cases involved the more classical tyrosine kinase domains of KIT (exon 13 and 17) in six out of seven cases. Intriguingly, we also found one gastric GIST with a primary KIT exon 13 mutation (Lys642Glu) which relapsed three years later under Imatinib, with a secondary mutation in PDGFRA exon 18 (Arg841_Asp842delinsLys). To the best of our knowledge, this is the second case reported so far of acquired resistance involving a different kinase from the one affected by the primary mutation [52]. Our results support the notion that the $B R A F$ mutation plays a minor role as a concomitant alteration in both primary and secondary resistance.

In order to optimize the method for detecting $B R A F$ mutated cases in GIST, we evaluated the expression of the mutation-specific antibody VE1 in a large series of GIST and compared the results with direct sequencing of $B R A F$ exon 15. Our findings indicate that VE1 antibody is highly sensitive for the presence of $B R A F \mathrm{~V} 600 \mathrm{E}$ mutation in GIST, as all six BRAF-mutated cases scored VE1 positive with moderate/strong staining intensity in four cases. Moderate/strong staining was detected exclusively in $B R A F$-mutated GIST, whereas none of the $B R A F$ mutation negative cases displayed such intensity. These findings indicate that significantly intense VE1 staining reliably predicts the presence of $B R A F$ mutation. This is in line with a recent study on a series of 38 GIST, in which VE1 strong expression was limited to the $2 B R A F$-mutant cases included [53]. Additionally, in that series, a weak VE1 staining was found only in a fraction of the $B R A F$ mutation negative cases [53]. Differently, in our series, 2 out of $6 B R A F$-mutant cases showed only a weak VE1 staining, as well as 14 out of 287 (4.9\%) BRAF wild-type cases. Hence, our results should caution the pathologist to interpret as either negative or positive for $B R A F$-mutation those GIST that show a weak VE1 expression. Instead, we consider that in presence of a weak staining, the molecular assessment of $B R A F$ gene status is highly recommended.

Although the frequency of the $B R A F$ mutation in GIST is limited $(<1 \%)$, the presence of this mutation has a high impact on patients' management. If on one hand it causes resistance to TK-inhibitors [18, 22], on the other it sensitizes the tumor to BRAF inhibitors. Falchook et al. recently reported a GIST case effectively treated with Dabrafenib [22]. NGS is gaining ground in the diagnostic setting, thus allowing for the simultaneous assessment of a wider set of molecular biomarkers. While waiting for this approach to be fully implemented by pathology laboratories, we believe that at the present time VE1 immunostaining may represent a valuable tool to address BRAF mutation status in GIST.

\section{MATERIALS AND METHODS}

\section{Tumor samples}

To investigate the role of $B R A F$ mutation in GIST, KIT (exon 9, 11, 13, 17), PDGFRA (exon 12, 14, 18) and $B R A F$ (exon 15) mutations were sequenced in a series of 407 cases (including 358 personal consultation cases referred to one of the authors [ADT], and 49 in-house cases) from 398 patients. Eight patients had multiple GIST either in the context of neurofibromatosis (three cases) or in a non-syndromic context (five cases) [54]. Informed consent was obtained from all living patients. Two hundred and fifteen were men and 183 were women. Age ranged between 24 and 91 years (median 63). Clinical records were available for 344 of the 398 patients. Two hundred and eighty-seven out of 353 tumors were primary GIST: 262 located in the gastrointestinal tract (142 gastric, 17 duodenal, 88 from the small intestine, one from the colon, 14 from the sigma-rectum) and 23 extra-gastrointestinal (12 from the abdominal cavity and pelvis, and nine from the retro-peritoneum). The remaining 68 cases were either relapsed or metastatic GIST.

The median size of the primary tumors was 5.5 $\mathrm{cm}$ (range 0.5 to $35 \mathrm{~cm}$ ) and the median mitotic index was $4 / 50 \mathrm{HPF}$ (range 0 to 180 ). The risk category could be determined in 221 cases on the basis of the AFIP classification (17 no risk, 13 very low, 61 low, 49 intermediate and 81 high risk tumors).

The predictive value of VE1 staining, as a surrogate for BRAF mutation analysis, could be assessed by immunohistochemistry on a subset of 21 (in-house) cases. Four GIST carrying the BRAF V600E mutation were retrieved from a previous series [17] and included as positive controls.

A further series of 288 cases, arranged in 25 tissue microarrays (TMA) deriving from a large population- 
based Italian study [17] [55], was also tested for VE1. Each tumour was represented by two to four cores in each array. In this study set, KIT/PDGFRA/BRAF status had previously been determined by sequential screening of the different exons until the mutation was detected, in the following order: KIT exon 11, KIT exon 9, PDGFRA exon 18, PDGFRA exons 12 and 14, KIT exons 13 and 17. Cases devoid of KIT/PDGFRA mutation were further investigated for BRAF V600 mutations [17]. Of these 288 cases, one was BRAF-mutated (V600E), 188 were KIT-mutated (165 with exon 11, 18 with exon 9, three with exon 13 and two with exon 17 mutation), 61 were PDGFRA-mutated (49 with exon 18, five with exon 14, six with exon 12 mutation), one case carried a double KIT mutation (Asn659Asp and Pro567Leu), and 38 were wild-type. Three of the 165 KIT exon 11 mutations were homozygous.

\section{Molecular analyses}

DNA was extracted from representative blocks of formalin-fixed/paraffin-embedded tissues with tumor cellularity greater than $80 \%$. 10- $\mu$ m-thick sections were deparaffinized by serial xylene/ethanol washings. DNA was extracted using the EZ1 Biorobot (Qiagen $\mathrm{GmbH}$ ). KIT, PDGFRA and BRAF mutation analysis was performed by PCR and Sanger sequencing using the ABI PRISM 3100 Genetic Analyzer (Applied Biosystems), as previously described [17] [51] [54].

\section{Immunohistochemistry}

Immunohistochemistry (IHC) was performed on freshly-cut 3- $\mu$ m-thick, paraffin-embedded tissue sections, using VE1 antibody specific for BRAF V600E mutation (clone VE1, Spring Bioscence, Pleasanton, CA). Only cases for which the block was available to provide freshly cut sections were included in the study. To optimize the method, a range of conditions were tested, in relation to both antibody dilution $(1: 25,1: 50,1: 100)$ and antigen retrieval ( $\mathrm{pH} 6$ and $\mathrm{pH} 9$ buffer). A series of 10 melanomas, eight with V600E mutation and two with alternative BRAF mutations (V600K, K601E), were used as positive and negative control cases, respectively.

The selected protocol included heat-induced epitope retrieval (PTLINK Dako) with high $\mathrm{pH}$ (pH9) and antigenantibody reaction at 1:100 dilution for 40 minutes (KIT ENVISION FLEX, Dako) in an automated immunostainer (Dako Autostainer, DakoCytomation, Glostrup, Denmark). For four BRAF-mutated cases, VE1 antibody was also tested on whole sections which had been cut seven years earlier. Notably, the intensity of the staining was much weaker than the results obtained on the freshly-cut sections, highlighting that the time gap between cutting and staining highly impacts on VE1 performance.
All immunostained slides were evaluated with blinding to clinical, histopathologic and genetic data by three histopathologists of varying experience. Interobserver agreement was high with approximately $10 \%$ of the cases re-reviewed collegially. Where there was any disagreement, the sections were re-reviewed and a consensus opinion reached.

Tumors were considered as positive when the tumor cells showed weak, moderate or strong cytoplasmic staining, and as negative when the tumor cells showed either faint cytoplasmic staining or no staining.

\section{CONFLICTS OF INTEREST}

The authors declare that they have no conflict of Interest.

\section{REFERENCES}

1. Davies H, Bignell GR, Cox C, Stephens P, Edkins S, Clegg $\mathrm{S}$, Teague J, Woffendin H, Garnett MJ, Bottomley W, Davis N, Dicks E, Ewing R, Floyd Y, Gray K, Hall S, et al. Mutations of the BRAF gene in human cancer. Nature. 2002; 417:949-954.

2. Michaloglou C, Vredeveld LC, Mooi WJ and Peeper DS. $\mathrm{BRAF}(\mathrm{E} 600)$ in benign and malignant human tumours. Oncogene. 2008; 27:877-895.

3. Minoo P, Moyer MP and Jass JR. Role of BRAF-V600E in the serrated pathway of colorectal tumourigenesis. The Journal of pathology. 2007; 212:124-133.

4. Schindler G, Capper D, Meyer J, Janzarik W, Omran H, Herold-Mende C, Schmieder K, Wesseling P, Mawrin C, Hasselblatt M, Louis DN, Korshunov A, Pfister S, Hartmann C, Paulus W, Reifenberger G, et al. Analysis of BRAF V600E mutation in 1,320 nervous system tumors reveals high mutation frequencies in pleomorphic xanthoastrocytoma, ganglioglioma and extra-cerebellar pilocytic astrocytoma. Acta neuropathologica. 2011; 121:397-405.

5. Tiacci E, Schiavoni G, Forconi F, Santi A, Trentin L, Ambrosetti A, Cecchini D, Sozzi E, Francia di Celle P, Di Bello C, Pulsoni A, Foa R, Inghirami G and Falini B. Simple genetic diagnosis of hairy cell leukemia by sensitive detection of the BRAF-V600E mutation. Blood. 2012; 119:192-195.

6. Long GV, Wilmott JS, Capper D, Preusser M, Zhang YE, Thompson JF, Kefford RF, von Deimling A and Scolyer RA. Immunohistochemistry is highly sensitive and specific for the detection of V600E BRAF mutation in melanoma. The American journal of surgical pathology. 2013; 37:6165.

7. Mathur A, Moses W, Rahbari R, Khanafshar E, Duh QY, Clark $\mathrm{O}$ and Kebebew E. Higher rate of BRAF mutation in papillary thyroid cancer over time: a single-institution study. Cancer. 2011; 117:4390-4395. 
8. Wan PT, Garnett MJ, Roe SM, Lee S, Niculescu-Duvaz D, Good VM, Jones CM, Marshall CJ, Springer CJ, Barford D, Marais R and Cancer Genome P. Mechanism of activation of the RAF-ERK signaling pathway by oncogenic mutations of B-RAF. Cell. 2004; 116:855-867.

9. Tannapfel A, Sommerer F, Benicke M, Katalinic A, Uhlmann D, Witzigmann H, Hauss J and Wittekind C. Mutations of the BRAF gene in cholangiocarcinoma but not in hepatocellular carcinoma. Gut. 2003; 52:706-712.

10. Samowitz WS, Sweeney C, Herrick J, Albertsen H, Levin TR, Murtaugh MA, Wolff RK and Slattery ML. Poor survival associated with the BRAF V600E mutation in microsatellite-stable colon cancers. Cancer research. 2005; 65:6063-6069.

11. Yokota T. Are KRAS/BRAF mutations potent prognostic and/or predictive biomarkers in colorectal cancers? Anticancer agents in medicinal chemistry. 2012; 12:163-171.

12. Brose MS, Volpe P, Feldman M, Kumar M, Rishi I, Gerrero R, Einhorn E, Herlyn M, Minna J, Nicholson A, Roth JA, Albelda SM, Davies H, Cox C, Brignell G, Stephens P, et al. BRAF and RAS mutations in human lung cancer and melanoma. Cancer research. 2002; 62:6997-7000.

13. Tian Q, Frierson HF, Jr., Krystal GW and Moskaluk CA. Activating c-kit gene mutations in human germ cell tumors. The American journal of pathology. 1999; 154:1643-1647.

14. Nagata H, Worobec AS, Oh CK, Chowdhury BA, Tannenbaum S, Suzuki Y and Metcalfe DD. Identification of a point mutation in the catalytic domain of the protooncogene c-kit in peripheral blood mononuclear cells of patients who have mastocytosis with an associated hematologic disorder. Proceedings of the National Academy of Sciences of the United States of America. 1995; 92:10560-10564.

15. Park C, Ha SY, Kim ST, Kim HC, Heo JS, Park YS, Lauwers G, Lee J and Kim KM. Identification of the BRAF $\mathrm{V} 600 \mathrm{E}$ mutation in gastroenteropancreatic neuroendocrine tumors. Oncotarget. 2016;7:4024-35. doi: 10.18632/ oncotarget.6602.

16. Doyle LA and Hornick JL. Gastrointestinal stromal tumours: from KIT to succinate dehydrogenase. Histopathology. 2014; 64:53-67.

17. Rossi S, Gasparotto D, Miceli R, Toffolatti L, Gallina G, Scaramel E, Marzotto A, Boscato E, Messerini L, Bearzi I, Mazzoleni G, Capella C, Arrigoni G, Sonzogni A, Sidoni A, Mariani L, et al. KIT, PDGFRA, and BRAF Mutational Spectrum Impacts on the Natural History of Imatinib-naive Localized GIST: A Population-based Study. The American journal of surgical pathology. 2015; 39:922-930.

18. Agaimy A, Terracciano LM, Dirnhofer S, Tornillo L, Foerster A, Hartmann A and Bihl MP. V600E BRAF mutations are alternative early molecular events in a subset of KIT/PDGFRA wild-type gastrointestinal stromal tumours. Journal of clinical pathology. 2009; 62:613-616.

19. Agaram NP, Wong GC, Guo T, Maki RG, Singer S,
Dematteo RP, Besmer P and Antonescu CR. Novel V600E BRAF mutations in imatinib-naive and imatinib-resistant gastrointestinal stromal tumors. Genes, chromosomes \& cancer. 2008; 47:853-859.

20. Hostein I, Faur N, Primois C, Boury F, Denard J, Emile JF, Bringuier PP, Scoazec JY and Coindre JM. BRAF mutation status in gastrointestinal stromal tumors. American journal of clinical pathology. 2010; 133:141-148.

21. Miranda C, Nucifora M, Molinari F, Conca E, Anania MC, Bordoni A, Saletti P, Mazzucchelli L, Pilotti S, Pierotti MA, Tamborini E, Greco A and Frattini M. KRAS and BRAF mutations predict primary resistance to imatinib in gastrointestinal stromal tumors. Clinical cancer research. 2012; 18:1769-1776.

22. Falchook GS, Trent JC, Heinrich MC, Beadling C, Patterson J, Bastida CC, Blackman SC and Kurzrock R. BRAF mutant gastrointestinal stromal tumor: first report of regression with BRAF inhibitor dabrafenib (GSK2118436) and whole exomic sequencing for analysis of acquired resistance. Oncotarget. 2013; 4:310-315. doi: 10.18632/ oncotarget.864.

23. Zheng S, Huang KE, Pan YL, Zhou Y, Pan SD, Li X, Jia J, Zheng XL and Tao DY. KIT and BRAF heterogeneous mutations in gastrointestinal stromal tumors after secondary imatinib resistance. Gastric cancer. 2014.

24. Skorokhod A, Capper D, von Deimling A, Enk A and Helmbold P. Detection of BRAF V600E mutations in skin metastases of malignant melanoma by monoclonal antibody VE1. Journal of the American Academy of Dermatology. 2012; 67:488-491.

25. Busam KJ, Hedvat C, Pulitzer M, von Deimling A and Jungbluth AA. Immunohistochemical analysis of BRAF(V600E) expression of primary and metastatic melanoma and comparison with mutation status and melanocyte differentiation antigens of metastatic lesions. The American journal of surgical pathology. 2013; 37:413420.

26. Boursault L, Haddad V, Vergier B, Cappellen D, Verdon S, Bellocq JP, Jouary T and Merlio JP. Tumor homogeneity between primary and metastatic sites for BRAF status in metastatic melanoma determined by immunohistochemical and molecular testing. PloS one. 2013; 8:e70826.

27. Colomba E, Helias-Rodzewicz Z, Von Deimling A, Marin C, Terrones N, Pechaud D, Surel S, Cote JF, Peschaud F, Capper D, Blons H, Zimmermann U, Clerici T, Saiag P and Emile JF. Detection of BRAF p.V600E mutations in melanomas: comparison of four methods argues for sequential use of immunohistochemistry and pyrosequencing. The Journal of molecular diagnostics : JMD. 2013; 15:94-100.

28. Marin C, Beauchet A, Capper D, Zimmermann U, Julie C, Ilie M, Saiag P, von Deimling A, Hofman P and Emile JF. Detection of BRAF p.V600E Mutations in Melanoma by Immunohistochemistry Has a Good Interobserver Reproducibility. Archives of pathology \& laboratory 
medicine. 2014; 138:71-75.

29. Koperek O, Kornauth C, Capper D, Berghoff AS, Asari $\mathrm{R}$, Niederle B, von Deimling A, Birner P and Preusser M. Immunohistochemical detection of the BRAF V600Emutated protein in papillary thyroid carcinoma. The American journal of surgical pathology. 2012; 36:844-850.

30. Zagzag J, Pollack A, Dultz L, Dhar S, Ogilvie JB, Heller KS, Deng FM and Patel KN. Clinical utility of immunohistochemistry for the detection of the BRAF v600e mutation in papillary thyroid carcinoma. Surgery. 2013; 154:1199-1204; discussion 1204-1195.

31. Zimmermann AK, Camenisch U, Rechsteiner MP, Bode-Lesniewska B and Rossle M. Value of immunohistochemistry in the detection of BRAF(V600E) mutations in fine-needle aspiration biopsies of papillary thyroid carcinoma. Cancer cytopathology. 2014; 122:48-58.

32. Crescenzi A, Guidobaldi L, Nasrollah N, Taccogna S, Cicciarella Modica DD, Turrini L, Nigri G, Romanelli F, Valabrega S, Giovanella L, Onetti Muda A and Trimboli P. Immunohistochemistry for BRAF(V600E) antibody VE1 performed in core needle biopsy samples identifies mutated papillary thyroid cancers. Hormone and metabolic research $=$ Hormon- und Stoffwechselforschung $=$ Hormones et metabolisme. 2014; 46:370-374.

33. Na JI, Kim JH, Kim HJ, Kim HK, Moon KS, Lee JS, Lee JH, Lee KH and Park JT. VE1 immunohistochemical detection of the BRAF V600E mutation in thyroid carcinoma: a review of its usefulness and limitations. Virchows Archiv : an international journal of pathology. 2015.

34. Ilie M, Long E, Hofman V, Dadone B, Marquette $\mathrm{CH}$, Mouroux J, Vignaud JM, Begueret H, Merlio JP, Capper D, von Deimling A, Emile JF and Hofman P. Diagnostic value of immunohistochemistry for the detection of the BRAFV600E mutation in primary lung adenocarcinoma Caucasian patients. Annals of oncology. 2013; 24:742-748.

35. Sasaki H, Shimizu S, Tani Y, Shitara M, Okuda K, Hikosaka Y, Moriyama S, Yano M and Fujii Y. Usefulness of immunohistochemistry for the detection of the BRAF V600E mutation in Japanese lung adenocarcinoma. Lung cancer. 2013; 82:51-54.

36. Ida CM, Vrana JA, Rodriguez FJ, Jentoft ME, Caron AA, Jenkins SM and Giannini C. Immunohistochemistry is highly sensitive and specific for detection of BRAF V600E mutation in pleomorphic xanthoastrocytoma. Acta neuropathologica communications. 2013; 1:20.

37. Bosmuller H, Fischer A, Pham DL, Fehm T, Capper D, von Deimling A, Bonzheim I, Staebler A and Fend F. Detection of the BRAF V600E mutation in serous ovarian tumors: a comparative analysis of immunohistochemistry with a mutation-specific monoclonal antibody and allele-specific PCR. Human pathology. 2013; 44:329-335.

38. Capper D, Berghoff AS, Magerle M, Ilhan A, Wohrer A, Hackl M, Pichler J, Pusch S, Meyer J, Habel A,
Petzelbauer P, Birner P, von Deimling A and Preusser M. Immunohistochemical testing of BRAF V600E status in 1,120 tumor tissue samples of patients with brain metastases. Acta neuropathologica. 2012; 123:223-233.

39. Routhier CA, Mochel MC, Lynch K, Dias-Santagata D, Louis DN and Hoang MP. Comparison of 2 monoclonal antibodies for immunohistochemical detection of BRAF $\mathrm{V} 600 \mathrm{E}$ mutation in malignant melanoma, pulmonary carcinoma, gastrointestinal carcinoma, thyroid carcinoma, and gliomas. Human pathology. 2013; 44:2563-2570.

40. Sinicrope FA, Smyrk TC, Tougeron D, Thibodeau SN, Singh S, Muranyi A, Shanmugam K, Grogan TM, Alberts SR and Shi Q. Mutation-specific antibody detects mutant BRAFV600E protein expression in human colon carcinomas. Cancer. 2013; 119:2765-2770.

41. Capper D, Voigt A, Bozukova G, Ahadova A, Kickingereder $\mathrm{P}$, von Deimling A, von Knebel Doeberitz $\mathrm{M}$ and Kloor M. BRAF V600E-specific immunohistochemistry for the exclusion of Lynch syndrome in MSI-H colorectal cancer. International journal of cancer Journal international du cancer. 2013; 133:1624-1630.

42. Toon CW, Walsh MD, Chou A, Capper D, Clarkson A, Sioson L, Clarke S, Mead S, Walters RJ, Clendenning M, Rosty C, Young JP, Win AK, Hopper JL, Crook A, von Deimling A, et al. BRAFV600E immunohistochemistry facilitates universal screening of colorectal cancers for Lynch syndrome. The American journal of surgical pathology. 2013; 37:1592-1602.

43. Affolter K, Samowitz W, Tripp S and Bronner MP. BRAF V600E mutation detection by immunohistochemistry in colorectal carcinoma. Genes, chromosomes \& cancer. 2013; 52:748-752.

44. Kuan SF, Navina S, Cressman KL and Pai RK. Immunohistochemical detection of BRAF V600E mutant protein using the VE1 antibody in colorectal carcinoma is highly concordant with molecular testing but requires rigorous antibody optimization. Human pathology. 2014; 45:464-472.

45. Sajanti S, Sirnio P, Vayrynen JP, Tuomisto A, Klintrup K, Makela J, Ristimaki A and Makinen MJ. VE1 immunohistochemistry accurately detects BRAF V600E mutations in colorectal carcinoma and can be utilized in the detection of poorly differentiated colorectal serrated adenocarcinoma. Virchows Archiv : an international journal of pathology. 2014; 464:637-643.

46. Lasota J, Kowalik A, Wasag B, Wang ZF, FelisiakGolabek A, Coates T, Kopczynski J, Gozdz S and Miettinen M. Detection of the BRAF V600E mutation in colon carcinoma: critical evaluation of the imunohistochemical approach. The American journal of surgical pathology. 2014; 38:1235-1241.

47. Piton N, Borrini F, Bolognese A, Lamy A and Sabourin JC. KRAS and BRAF Mutation Detection: Is Immunohistochemistry a Possible Alternative to Molecular Biology in Colorectal Cancer? Gastroenterology research 
and practice. 2015; 2015:753903.

48. Adackapara CA, Sholl LM, Barletta JA and Hornick JL. Immunohistochemistry using the BRAF V600E mutation-specific monoclonal antibody VE1 is not a useful surrogate for genotyping in colorectal adenocarcinoma. Histopathology. 2013; 63:187-193.

49. Sperveslage J, Gierke M, Capper D, Honegger J, Sipos B, Beschorner R and Schittenhelm J. VE1 immunohistochemistry in pituitary adenomas is not associated with BRAF V600E mutation. Acta neuropathologica. 2013; 125:911-912.

50. Schafroth C, Galvan JA, Centeno I, Koelzer VH, Dawson HE, Sokol L, Rieger G, Berger MD, Hadrich M, Rosenberg $R$, Nitsche U, Schnuriger B, Langer R, et al. VE1 immunohistochemistry predicts BRAF V600E mutation status and clinical outcome in colorectal cancer. Oncotarget. 2015; 6:41453-41463. doi: 10.18632/oncotarget.6162.

51. Rossi S, Gasparotto D, Toffolatti L, Pastrello C, Gallina G, Marzotto A, Sartor C, Barbareschi M, Cantaloni C, Messerini L, Bearzi I, Arrigoni G, Mazzoleni G, Fletcher JA, Casali PG, Talamini R, et al. Molecular and clinicopathologic characterization of gastrointestinal stromal tumors (GISTs) of small size. Am J Surg Pathol. 2010; 34:1480-1491.

52. Debiec-Rychter M, Cools J, Dumez H, Sciot R, Stul M, Mentens N, Vranckx H, Wasag B, Prenen H, Roesel J, Hagemeijer A, Van Oosterom A and Marynen P. Mechanisms of resistance to imatinib mesylate in gastrointestinal stromal tumors and activity of the
PKC412 inhibitor against imatinib-resistant mutants. Gastroenterology. 2005; 128:270-279.

53. Patil DT, Ma S, Konishi M, Carver PD, Pukay M, Beadling C, Corless CL and Rubin BP. Utility of BRAF V600E Mutation-Specific Immunohistochemistry in Detecting BRAF V600E-Mutated Gastrointestinal Stromal Tumors. Am J Clin Pathol. 2015; 144:782-789.

54. Gasparotto D, Rossi S, Bearzi I, Doglioni C, Marzotto A, Hornick JL, Grizzo A, Sartor C, Mandolesi A, Sciot R, Debiec-Rychter M, Dei Tos AP and Maestro R. Multiple primary sporadic gastrointestinal stromal tumors in the adult: an underestimated entity. Clin Cancer Res. 2008; 14:5715-5721.

55. Rossi S, Miceli R, Messerini L, Bearzi I, Mazzoleni G, Capella C, Arrigoni G, Sonzogni A, Sidoni A, Toffolatti L, Laurino L, Mariani L, Vinaccia V, Gnocchi C, Gronchi A, Casali PG, et al. Natural history of imatinib-naive GISTs: a retrospective analysis of 929 cases with long-term followup and development of a survival nomogram based on mitotic index and size as continuous variables. Am J Surg Pathol. 2011; 35:1646-1656. 